Indonesian Journal of EFL and Linguistics

Vol. 3 No. 1, 2018

eISSN: 2503-4197, pISSN: 2527-5070

www. indonesian-efl-journal.org

\title{
Providing Explicit Language Instruction to Assist Students' Language Learning in EFL Classrooms
}

\author{
Suci Noer Wulan Sari \\ Universitas Pendidikan Indonesia, Indonesia \\ e-mail: sucinoerwulansari@ student.upi.edu
}

\begin{abstract}
:
In language teaching process, instruction becomes one of important things to provide in order to encourage students' language learning. Since the late 1960s, one of the language instructions that has been available is explicit language instruction which is believed as one of useful tools for the teaching practice. Given that the present study tried to investigate how English lecturers provide explicit language instruction in EFL classrooms to assist their students' language learning. To gain the data, a case study employing semi-structured interviews and classroom observations were conducted. Two English lecturers were purposively selected to be the participants of the study for their familiarity of the instruction. Based on the analysis, the study revealed some of the elements of explicit language instruction provided such as clearly stating the lesson's objectives and teachers' expectations, using language clearly and concisely, providing step-by-step demonstrations and adequate examples, guiding students through practices on language functions, monitoring student performance and responses by giving feedbacks, and encouraging students to organize knowledge. It can be concluded that explicit language instruction actually can be considered for classroom improvement. Future studies are suggested to investigate students' voices of the implementation of the instruction that may actually help their lecturers better their teaching practices and favour their students' learning outcomes.
\end{abstract}

Keywords: explicit language instruction, language learning, EFL classrooms

Indonesian Journal of EFL and Linguistics, Vol. 3(1), 2018 


\section{INTRODUCTION}

Language is the tool for transferring meaning from mind to mind (Lakoff, 2000). By using language, we try to make meaning. Moreover, we use it to build an interaction and get things done. In the context of teaching English as a foreign language, teachers might have some considerations; one of which is language instruction. Language instruction is a series of actions which has goal to provide possibilities that may favour the acquisition of second language (Nasaji, 2017). Bot, Lowie, \& Verspoor (2005) pointed out that the instruction provided is indeed evident to have positive impact on students' learning. Given that there is a necessity to provide language instruction to support students' learning which eventually may lead to better performances and outcomes.

One of existing language instructions is explicit instruction. It can be referred as a systematic, organized, and useful methodology for teaching academic skills (Archer \& Hughes, 2011; Hall \& Vue, 2014). It provides scaffolding or supports in which students are guided through the learning process. Archer \& Hughes (2011) tried to note three core components of the instruction: clear delivery procedures, guided practices, and gradual teacher's support withdrawal towards student independent performance. Moreover, they tried to exemplify the characteristics of explicit instruction identified by many researchers adapted them into Sixteen Elements of Explicit Instruction.

Previously, Rahimpour \& Salimi (2010), Aufa (2011), Ballou (2012), Hall \& Vue (2014), Talley \& Hui-ling (2014), and Nezakat-Alhossaini, Youhanaee, \& Moinzadeh (2014) conducted studies on explicit instruction. Some of the studies focused on improving a certain skill (e.g. speaking, grammar, and pragmatic). Meanwhile, Ballou (2012) pointed out that students' attitudes toward reading and ability in using a wide range of strategies improved. Considering those previous studies, the present study was aimed at investigating how explicit language instruction is provided to assist students' language learning in EFL classrooms. The study can be considered for classroom improvement (e.g. as a method employed to improve students' language learning) since explicit language instruction is believed effective for educators which may favour both their teaching practice and students' language learning performances and outcomes.

\section{LITERATURE REVIEW}

\subsection{Explicit Language Instruction}

Since the late 1960s, one of the existing language instructions for the teaching practice is explicit instruction (Hall \& Vue, 2014). They defined explicit instruction as an organized teaching approach that has two main elements: set of apparent delivery and clear instructional design procedures. The instruction involves modelling, step-by-step demonstration, guided practices, skill practices, skills linkage, clear statements about the lesson, and student interest elicitation (Rupley, Blair, \& Nichols, 2009 in Hall \& Vue, 2014). Moreover, it can be referred as a well- 
designed methodology for teaching academic skills (Archer \& Hughes, 2011). They further defined the instruction as a systematic, organized, and efficacious methodology since it serves to provide scaffolds or supports in which students are guided through the learning process. Moreover, they pinpointed that there are three central phases of explicit instruction: certain delivery procedures, guided practices, and gradual teacher's support withdrawal towards student independent performance.

\subsection{Elements of explicit language instruction}

Archer \& Hughes (2011) tried to adapt the characteristics of explicit instruction into sixteen elements such as: (1) Focusing instruction on critical content; (2) Sequencing skills logically; (3) Breaking down complex skills and strategies into smaller instructional units; (4) Designing organized and focused lessons; (5) Starting lessons with a clear statement of the lesson's goals and your expectations; (6) Reviewing prior skills and knowledge before beginning instruction; (7) Providing step-by-step demonstrations; (8) Using clear and concise language; (9) Providing an adequate range of examples and non-examples; (10) Providing guided and supported practice; (11) Requiring frequent responses; (12) Monitoring student performance closely; (13) Providing immediate affirmative and corrective feedback; (14) Delivering the lesson at a brisk pace; (15) Helping students organize knowledge; and (16) Providing distributed and cumulative practice.

Based on the elements mentioned above, it can be concluded that initially, teachers should provide the clear goal and rationale for learning the new skill. So that, students can understand why they need to study that certain material. They can also notice how to reach the possible learning outcome. Step-by-step demonstrations on the skills are also important to be provided. By giving clear explanation to students, they can learn for the model of advanced performance. For example, when learning a certain grammar, students can learn from the rules provided and understand from their teacher's modelling. Moreover, teachers need to encourage initial success of the learning by providing supported and guided practices in which leads students to eventually work independently by themselves without teacher's help. When students learn the skills, they need to monitor their performance closely. They may provide feedback either affirmative or corrective ones to reduce possible errors in the future.

Considering the elements of the instruction, it is clear that students will be guided through the learning process that may actually lead them to better performances and learning outcomes. Given that explicit instruction can be considered as one of effective tools in learning and teaching academic skills available for educators.

\subsection{Language Learning}

Language learning can be defined as the result of activities that empowers the increase of knowledge (Bot, Lowie, \& Verspoor, 2005). Krashen (1981) considered language learning as the result of formal teaching producing 'conscious' knowledge of the language learned. Since learning here results conscious knowledge, it is believed that feedback and the explanation of explicit rules may help activate it (Krashen \& Seliger, 1975; in Krashen, 1981). Providing immediate corrective and affirmative feedbacks actually may be helpful for students when they are making

Indonesian Journal of EFL and Linguistics, Vol. 3(1), 2018 
errors in their learning (Archer \& Hughes, 2011). Moreover, demonstrating step-bystep rules explicitly to students and monitoring their responses may favour them to comprehend the skills better (Hall \& Vue, 2014).

Generally, language learning is distinguished into implicit versus explicit learning. (Ellis, 1994). He explained that implicit learning undertakes without needs on 'attentional resources'. In implicit learning, students seems to be unaware of the learning occurring. Meanwhile, explicit learning mostly takes place by memorization of 'successive facts' which produces to conscious knowledge. On the other hand, Bot, Lowie, \& Verspoor (2005) tried to explain learning in terms of incidental and intentional. They pointed out that incidental learning can be in the form of 'learning words by reading and inferring meanings from context.' Intentional learning can take place when the teacher asks the students to read a text and identify the meanings of unfamiliar words, for example. Given that since there are kinds of learnings that can take place, it would be wise that teachers to facilitate their students learning with their instruction for a better student performances and outcomes.

\subsection{Providing explicit language instruction to assist students' language learning in EFL classrooms}

Previously, some studies on explicit instruction to favour students' language learning have been conducted. Some are the works of Talley \& Hui-ling (2014), Nezakat-Alhossaini, Youhanaee, \& Moinzadeh (2014), Ballou (2012), Aufa (2011) and Rahimpour \& Salimi (2010).

Talley \& Hui-ling (2014) tried to investigate explicit and implicit instruction in the EFL classroom. They pointed out that teachers provide explicit instruction by giving rules to learn and practice consciously. Meanwhile, implicit instruction is facilitated through planned supports of strategies instruction and providing comprehension and memorization as well. Since they focused on EFL language speaking instruction, they suggested that in order to reach the purpose of both implicit and explicit instruction, the curriculum should be designed with two main principles: exposing students to authentic and practical contexts, and encouraging them to get actively engaged in English speaking for communication in the classroom context.

Nezakat-Alhossaini, Youhanaee, \& Moinzadeh (2014) investigated the effect of explicit instruction on the acquisition of English especially in passive objective relative clauses. They involved two group participants (experimental and control). The experimental group consisting of 16 advanced EFL learners were provided with explicit instruction on the target structure. Meanwhile, the control group consisting of 15 intermediate EFL learners did their routine activities in a writing class. The findings showed that there was a positive effect of explicit instruction for both explicit and implicit knowledge for the experimental group.

Ballou (2012) conducted a study on using explicit strategy instruction to improve reading comprehension. Three students and teachers became her participants. The three students were explicitly taught during reading comprehension strategies. After that, they were provided with pre and post-test to find out the effectiveness and 
implications of the instruction. Moreover, a questionnaire related to reading comprehension were given to teachers when the study was conducted. The findings revealed that there was no improvement in students' comprehension scores; however, there was improvement in their attitudes toward reading, and ability to employ a wide range of strategies after providing with explicit strategy instruction. She suggested that teachers should try to optimize their time in providing explicit strategy instruction to get optimum benefits of the instruction.

Aufa (2011) tried to investigate the effect of Discourse Completion Task (DCT) as explicit instruction to facilitate Indonesian EFL learners in improving their pragmatic competence. The study resulted in several variations of linguistic forms which serve to provide the development of learners' pragmatic competence. It indicate that they could improve their input of suggestion act after applying the prompted DCT in their learning. Since they received explicit instruction on some variables such as social distance, power, and the degree of imposition and were guided in the learning, they could understand particular features of pragmatic input, functions, social contexts and cultural meanings as well. Thus, it can be conclude that DCT as explicit instruction could favour EFL learners' pragmatic competence. The study also suggested to employ various teaching techniques to overcome issues encountered on teaching pragmatic in EFL classrooms.

Rahimpour \& Salimi (2010) investigated the impact of explicit instruction on foreign language learners' performance. They employed quantitative research design using grammatical judgement test as the instrument. Around 30 female students of English at an intermediate level were randomly selected as the study sample. Statistical analysis employing T-test was used to prove their hypothesis. The result indicates that there was a significant difference between explicit formal instruction and foreign language learners' performance.

\section{RESEARCH METHODOLOGY}

Since the study was aimed at investigating how English lecturers provide explicit language instruction to assist their students' language learning in EFL classrooms, the present study employed a case study design. The kind of design was chosen since it was aimed to gain an in-depth description on the phenomenon (Merriam, 2009); moreover, there was no intervention during the process of collecting the data.

\subsection{Context of the Study, Research Site, and Participants}

The study only focused on one of language instructions which is explicit language instruction in college context. Thus, it was conducted at one of colleges, particularly in English language laboratory, in Bandung. The participants were two English lecturers namely Salma and Yunus (pseudonyms). They were selected purposefully for the justification of their familiarity with explicit language instruction.

\subsection{Data Collection Techniques}

The study involved semi-structured interviews to obtain more information on a certain topic (Harrell and Bradley, 2009), and classroom observations to serve as 'the knowledge of the context' (Merriam, 2009) which is how English lecturers

Indonesian Journal of EFL and Linguistics, Vol. 3(1), 2018 
provide explicit language instruction to assist their students' language learning in EFL classrooms. Additionally, a comprehensive understanding can be provided based on the data analysis. Initially, the interviews were carried out in order to answer the research question stated before. Meanwhile, classroom observations were conducted to triangulate the data obtained from the interviews. Below are the procedures of conducting the interviews and observations.

Initially, the two participants were asked for the agreements for the interviews. After there were agreements, both of them were interviewed at the different time due to their different class schedules. Salma was interviewed on November 18, 2017, meanwhile Yunus was on November 21, 2017. I asked them how they provide explicit instruction. During the interview sessions, there were some questions changed to dig more answers provided by them.

The observations were conducted at the same day after each participant was interviewed. During the observations, I used the observation checklist regarding the 16 Elements of Explicit Language Instruction adapted by Archer \& Hughes (2011) in order to triangulate the data from the interview. It was to see if they provided the elements of the instruction based on what they explained in the interview sessions.

\subsection{Data Analysis}

The data analysis employed Miles and Huberman's (1994) Interactive Model: data reduction, data display, and conclusion drawing or verification. The raw data gathered from the interviews and observations was reduced by selecting, simplifying, and focusing only on how the English lecturers provide explicit language instruction in order to assist their students' language learning. The data reduced was displayed in the form of theme categorization. The themes appeared were: clearly stating the lesson's objectives and teachers' expectations, using language clearly and concisely, providing step-by-step demonstrations and adequate examples, guiding students through practices on language functions, monitoring student performance and responses by giving feedbacks, and encouraging students to organize knowledge. The data was described in analysis section in order to discuss and answer the research question: How do English lecturers provide explicit language instruction to assist their students' language learning?

\section{FINDINGS AND DISCUSSION}

Explicit language instruction is believed as one of the efficacious tools for educators in the teaching practice (Archer \& Hughes, 2011; Hall \& Vue, 2014). Based on the interviews and observations I conducted for collecting the data, here are the ways how the two participants: Salma and Yunus (pseudonyms) tried to provide the instruction in order to encourage their students' language learning in EFL classrooms.

\subsection{Stating the lesson's objectives and their expectations clearly}

When it comes to teaching, teachers should let their students know the lesson's objectives, and also their expectations to make their students aware of their learning. 
Based on the interview, Salma pointed out that she stated the learning objectives to her students as follows.

Line 54 : "I expect the materials are understandable by the students."

Line $57:$ : "...the purpose in the opening. Yes, because my target is to make the students master the materials."

Line 67-68 : "I elaborate it to their daily contexts so they could understand the goal of the learning and they can apply that in daily *life."

On the other hand, Yunus did not explain if he stated the lesson's objectives in his teaching practices when was being asked how he started his teaching. It could be assumed that he forgot to explain about it. He only mentioned that he started his teaching with greetings.

Line 17 : "I start my teaching activity of course with you know technically like say hi and then greeting with a little bit of the game..."

Seen from Salma's responses above, it is apparent that stating the lesson's objectives and expectations is clearly important. What she stated is in accordance with Archer \& Hughes (2011) that giving clear lesson's goals and expectations aims at letting them understand what possible outcomes they should reach at the end of the lesson. Considering how important it is to state the lesson's goals and expectations to students, Salma wanted her students understand the lesson's goals and more importantly to apply the learning in daily context. Meanwhile, Yunus seemed to forget mentioning about the lesson's objectives and expectations to his students. Yet, it would be further observed in his teaching practice during classroom observation to find out if he mentioned the lesson's objectives and expectations.

During the observations, it was seen that both Salma and Yunus mentioned the topic that the students would be learning. Since they were observed on the different days, the materials delivered were different. The topic in Salma's class was Modals. The lesson included some practices on reading, vocabulary acquisition, listening, and speaking. Initially, it seemed that she tried to ask her students regarding the material they were going to learn without telling them her expectations for the lesson. She also tried to present information by relating the lesson to daily context. In some practices regarding the functions of Modals, the lesson's objectives were clear, which was to make students use appropriate Modals based on the functions. Similarly, Yunus mentioned the topic by briefly saying, "We are going to learn about Passive Voice." However, he tried to explain the lesson's objectives by giving some rules of Passive Voice written on the whiteboard which later on he tried to teach to his students as a review from the lesson taught at the previous class. It could be said that what he did at the language laboratory actually was done in order to make his students understand the lesson's objectives. Moreover, some students seemed to be attentive when he explained the lesson. While some seemed get distracted because they sat behind.

Based on the explanation above, it is clear that the lesson's objectives and expectations are essential to be stated at the beginning in order to make students 
aware and focus on the learning, and more importantly understand why they need to learn that skill and know what to do to reach possible learning outcomes (Archer \& Hughes, 2011). However, when teaching and learning processes take place, it seems that even though teachers try their best to state the lesson's objectives and their expectations for their students' learning, only some students pay attention for some reasons. Thus, they need to condition their students to focus on the goals and help them reach those goals in a more engaging learning environment though it would take time.

\subsection{Using clear and concise language}

Language is the tool for transferring meaning from mind to mind (Lakoff, 2000). In order to teach academic skills to students, a clear and concise language is one of the elements in explicit language instruction. Based on the interviews, both Salma and Yunus were not asked about their use of language for their classes. However, during the observations, it was seen that both of them tried to use language clearly and concisely. Most of the time they tried to explain the lesson in English to give their students exposure to the language. However, sometimes they employed Indonesian language to check if their students understood what they explained or the instruction they provided.

Salma tried to explain the terms in vocabulary acquisition in order to let them understand what they meant. In other words, she explicitly translated them to her students. It could be assumed that she might want them to understand the words quickly. Moreover, it might be for saving time for working on some practices of the lesson. Despite the fact she literally translated the terms into Indonesian language, she tried to check her students' understanding after she explained the lesson. Once they understood, she moved to other practices. Similarly, Yunus tried to use the language clearly to his students. He frequently asked them if they understood. When he asked them, one student raised his hand and asked him to explain one more time. He then tried to explain the lesson until they understood.

It can be said that what they did is in line with Archer \& Hughes (2011) that providing explicit instruction requires the use of clear and concise language. However, they mentioned that it should depend upon students' receptive vocabulary. Given that teachers need to be aware of their students' vocabulary in order to make them comprehend the lesson and their instruction as well.

\subsection{Providing clear step-by-step explanations and adequate examples}

In teaching academic skills, it is important to provide clear step-by-step demonstrations and adequate examples to students. For instance, they may learn from the modelling provided by their teachers. Based on the interviews, Salma and Yunus stated that they tried to explain the lesson clearly. Here are some of their responses.

Line 29-31 : “...give some modelling about the good sentences by using certain tenses, certain contexts, and then ask them to make 
the similar sentence, similar pattern, based on the context given." (Salma)

Line 75-77 : "I just lead them to the point. I teach them 'this is the main idea, this is making inference, this is you know true or false implicit or explicit' something like that." (Yunus)

Line 78-81 : "I demonstrate some of the strategies for example like I found one paragraph so I compare with other paragraphs which is made by me so we can find some similarities to be *dealt with." (Yunus)

Seen from Salma's responses, it seems that she wanted her students to learn from the modelling she gave, for example, when teaching a certain tense, she modelled some sentences using that particular tense. Moreover, she asked her students to make sentences after she explained. That could mean that she wanted to check if they understood from the modelling she gave. However, Yunus, in teaching another skill which is reading, seemed to teach the reading strategies explicitly like he mentioned like finding out a main idea, making inference and others. By providing demonstration on teaching reading strategies, he expected that his students could understand better in comprehending texts.

During the observation, Salma tried to read the text to her students in order to let them know how to pronounce the words better and gave some examples in vocabulary acquisition session. However, it was not apparent that she provided stepby-step explanations on the topic. This was assumed that the students might have received the lesson previously at the class; so that, she did not need to demonstrate the topic at the laboratory. Therefore, she rather gave a step-by-step instruction when it came to practices and checked if her students understood what they needed to do. On the other hand, Yunus tried to review the topic by writing the rules of Passive Voice on the whiteboard. Moreover, he tried to model the sentences in the form of Passive Voice. After writing the rules and examples, he tried to explain the topic step-by-step especially when changing the active voice sentences into passive voice ones. He further invited the students to change the sentences by themselves to see if they understood the topic.

What those participants said and did are in accordance with Archer \& Hughes (2011), Rupley, Blair, \& Nichols (2009) in Hall \& Vue (2014), and Hui-ling and Talley (2014). They pointed out that giving step-by-step explanations or demonstrations to students for a better learning is required. Apparently, Salma did not provide step-by-step demonstrations of the topic in her teaching practice on that day though she mentioned she usually gave modelling. It could happen for the assumption the students already had enough explanation on the topic at the previous class. Yet, giving step-by-step instruction to complete a task is still included in the element of providing step-by-step explanations/demonstrations (Archer \& Hughes, 2011). Following Aufa (2011) who investigated the effect of explicit instruction in improving Indonesian EFL learners' pragmatic competence, guidance given by the lecturer could favour their pragmatic competence especially in giving suggestion in English. Related to the present study, it was seen that by giving guidance through

Indonesian Journal of EFL and Linguistics, Vol. 3(1), 2018 
step-by-step demonstration to students, they could learn better through what has been modelled by the lecturer. Therefore, it is apparent that providing step-by-step explanations and adequate examples to enhance their students' language learning is essential for teachers to perform in their teaching practice.

\subsection{Encouraging students with guided and supported practices on language functions}

Based on the interviews, both Salma and Yunus tried to provide adequate guided and supported practices to their students. Here are what they stated.

Line 70-71 : "....I usually give them some you know tasks to be discussed with the friends. And then they present it." (Salma)

Line 34-37 : "For giving practices to the students it depends on the material which is given by the official. For example, if there is a speaking session, I give them the speaking. But, if there is no speaking activity in the class, sometimes I do or even sometimes not. It depends on the mood that can be seen in the students itself." (Yunus)

It seemed that Salma wanted her students to practice the lesson explained by discussing with their peers. It could be helpful when some students have not understood, so they could ask their peers to explain to them. However, it might be harmful at the same time if some students tend to take discussion for granted, for instance, by letting their peers work without giving some helps. Given that it would be wise to monitor students when assigning them to work on discussion. Meanwhile, Yunus tried to give some practices designed by the official. However, he tried to give another practice and considered if that would suit his students' mood during the learning.

During the observation, it could be seen that Salma read the text to her students and gave some instructions to work on task 1 until the last one. Her students seemed to be focused on working on the practices. Some of them tried to discuss with their peers when they did not understand the practice they were working on. On the other hand, Yunus started with listening session regarding the material of Passive Voice. His students seemed to focus themselves in order to work on the practice.

It can be summed up that what they stated and performed in their teaching practices are in accordance with Archer \& Hughes (2011) and Rupley, Blair, \& Nichols (2009) in Hall \& Vue (2014) that another component of explicit instruction is guiding students through practices - supported and guided ones. Thus, there is a necessity to provide some practices in order to promote initial learning success.

\subsection{Monitoring student performance: providing immediate and corrective feedbacks}

Salma and Yunus also pointed out that they tried to monitor their students and provided feedbacks especially when they were making errors. Here are their responses in the interview sessions.

Indonesian Journal of EFL and Linguistics, Vol. 3(1), 2018 
Line 43-45 : "I divide the class into four groups and I ask one of the members of the group to be the representative. The representative will try to answer the description needed for the words I wrote in the whiteboard." (Salma)

Line 91-92 : "If it's in form of writing, I give feedback /written feedback/ If it's in form of presentation, I'll let them to finish it first then I give the feedback in the end." (Salma)

Line 31-32 : "Having been finished the task, I give directly the feedback until so forth and so forth. In the last I give them overall feedback for the meeting." (Yunus)

Salma stated that she monitored her students by dividing the students into groups and asked them to answer the questions. Moreover, she tried to give written and spoken feedbacks based on what kind of material she taught. On the other hand, Yunus tried to give his feedbacks directly mostly after his students completed the tasks and overall feedbacks at the end of the session.

In the classroom, Salma tried to monitor her student performances closely. She invited them to speak up about the topic. It seemed that she directly gave some feedbacks when her students were making errors. Sometimes, she paused and let them finished talking, then proceeded to provide her feedbacks. For instance, after completing the task 2, when the students answered incorrectly, she immediately provided some feedbacks. She said, "No, it's not. It should be..." Most of the students tried to receive the feedbacks. Similarly, Yunus tried to ask and monitor his student performances or responses closely if they made some errors or not. Most of the times, he provided immediate feedbacks when they answered incorrectly, so they could know the correct ones.

Based on their responses and their actual monitoring and feedbacks giving, it is in accordance with Archer \& Hughes (2011) and Hall \& Vue (2014). Monitoring student performances or responses and providing feedbacks could be helpful to find out students' understanding and reduce possible repeating errors. Following Tode (2007) in Nezakat-Alhossaini, Youhanaee, Moinzadeh (2014), there should be a need to provide follow-up practices together with corrective feedback in the learning. That would be wise to consider what kind of suitable feedbacks to be provided to students when they make errors either it should be affirmative or corrective. Given that we need to bear in mind that not all students would be aware of not repeating the same errors since it would take time for them to understand and learn.

\subsection{Encouraging students to organize their knowledge of the lesson}

The participants also mentioned about encouraging students to organize knowledge. Here are their responses.

Line 46-47 : "I will stimulate their understanding about or I will stimulate their knowledge about what I am going to teach..." (Salma)

Line 95 : "I invite students to summarize the learning."(Salma) 
Line 62-65 : "To provide the teaching especially the grammar I relate it to reality life for example in Present Continuous I start practicing miming you know something like that and so in order to make them comprehend about the Past Tense I start with telling a story and then to make them comprehend about Present I tell them about daily activities." (Yunus)

It could be seen that both of them tried to stimulate their students' understanding and relate the material to some contexts. For instance, by relating the material to daily context, it means that they wanted their students to see the linkage between the lessons and reduce students' difficulty in understanding the lessons. This is in accordance with Archer \& Hughes (2011) that encouraging students to organize their knowledge could connect information and integrate the new skills with previously acquired.

What they stated in the interview was apparent during the observations. Salma tried to ask her students regarding the text on Deciding Future Career and linked it to daily context by asking them how they felt about studying related to their future careers. Meanwhile, Yunus let his students think and answer the questions regarding Passive Voice. He also encouraged them to organize their knowledge. For instance, he questioned them like "Really? How about this?" so on and so forth. Some students seemed to think about the rules they learned, meanwhile some seemed to get lost. Still, he managed to explain more when he found out they still did not understand. Given that it is clear that teachers need to help their students organize their knowledge better to see the linkage between the lessons, and more importantly to understand the lesson they learn.

Based on the explanations above, the participants tried to provide the explicit language instruction in their EFL classrooms by clearly stating the lesson's objectives and teachers' expectations, using language clearly and concisely, providing step-by-step demonstrations and adequate examples, guiding students through practices on language functions, monitoring student performance and responses by giving feedbacks, and encouraging students to organize knowledge. By providing the explicit language instruction in the teaching practice, it is evident that students' language learning could be favoured.

\section{CONCLUSION}

From the discussions above, it can be concluded that explicit language instruction can be considered as an effective tool for teaching academic skills. Moreover, it may significantly contribute to classroom improvement as the method employed by lecturers to improve their students' language learning. However, that would be wise to take into account that the instruction is not the only shortcut for the success of the language learning.

Since the present study was only focused on investigating how English lecturers provide explicit language instruction to assist their students' language learning, I strongly suggest that future studies to investigate students' voices regarding the implementation of the instruction to see how useful it is based on their perspectives 
and experiences. It would be wise to acknowledge the students' voices to actually help lecturers better their teaching practices. Given that a semi-structured interview may be carried out to students to reveal how they perceive that the instruction may help their language learning.

\section{REFERENCES}

Archer, A.L., \& Hughes, C. A. (2011). Explicit instruction: Effective and efficient teaching. New York: The Guilford Press.

Aufa, F. (2011). The use of Discourse Completion Task (DCT) as explicit instruction on Indonesian EFL learners' production of suggestion acts. Journal of English and Education, 5(2) 21-43. Retrieved [March 3, 2018] from: https://www.neliti.com/publications/222300/the-use-of-discourse-completiontask-dct-as-explicit-instruction-on-indonesian-e

Ballou, A. K. (2012). Using explicit strategy instruction to improve reading comprehension. Manuscript of Master thesis. Fisher Digital Publications. St. John Fisher College. Retrieved [October 20, 2017] from: http://fisherpub.sjfc.edu/education_ETD_masters/221

Bot, K. de., Lowie, W., \& Verspoor, M. (2005). Second language acquisition: An advanced resource book. Oxon: Routledge.

Ellis, R. (1994). The study of second language acquisition. Oxford: Oxford University Press.

Hall, T., \& Vue, G. (2014). Explicit instruction. Wakefield, MA: National Center on Accessing the General Curriculum. Retrieved [October 20, 2017] from http://aem.cast.org/about/publications/2002/ncac-explicit-instruction.html

Harrell, M. C., \& Bradley, M. A. (2009). Data collection methods: Semi-structured interviews and focus groups. USA: RAND Corporation.

Krashen, S. D. (1981). Second language acquisition and second language learning. Pergamon Press Inc.

Lakoff, R. T. (2000). The language war. California: University of California Press.

Merriam, S. B. (2009). Qualitative research: A guide to design and implementation. California: John Wiley \& Sons, Inc.

Miles, M. B., \& Huberman, A. M. (1984). Qualitative data analysis: A sourcebook of new methods. California: SAGE Publications Inc.

Nasaji, H. (2017). Language instruction and language acquisition: A complex interplay. Language Teaching Research 2017, 2(5), 543-545. doi: $10.1177 / 1362168817727203$.

Nezakat-Alhossaini, M., Youhanaee, M., \& Moinzadeh, A. (2014). Impact of explicit instruction on EFL learners' implicit and explicit knowledge: A case of English relative clauses. Journal of Language and Linguistic Studies, 10(2), 183-199. Retrieved [October 22, 2017] from: dergipark.gov.tr/download/article-file/104821

Rahimpour, M., \& Salimi, A. (2010). The impact of explicit instruction on foreign language learners' performance. Procedia Social and Behavioral Sciences 2, 1740-1746. doi: 10.1016/j.sbspro.2010.03.976

Indonesian Journal of EFL and Linguistics, Vol. 3(1), 2018 
Talley, P. C., \& Hui-ling, T. (2014). Implicit and explicit teaching of English speaking in the EFL classroom: Concept and paradigm. International Journal of Humanities and Social Science 4(6), 38-46. Retrieved [October 18, 2017] from: www.ijhssnet.com/journals/Vol_6_No_4_April_2016/25.pdf 